\title{
Exploring the corrosion inhibition effect of two hydrazone derivatives for mild steel corrosion in 1.0 M HCl solution via electrochemical and surface characterization studies
}

\author{
Abdelkarim Chaouiki ${ }^{l}$, Maryam Chafiq ${ }^{1}$, Mustafa R. Al-Hadeethi ${ }^{2}$,Hassane Lgaz ${ }^{3 *}$, RachidSalghi ${ }^{1}$, \\ Siham K. AbdelRaheem ${ }^{4}$, Ismat H. Ali ${ }^{4}$, Sara A. M. Ebraheem ${ }^{4}$, Ill-Min Chung ${ }^{3 *}$, Shaaban K. \\ Mohamed $^{5,6}$ \\ ${ }^{1}$ Laboratory of Applied Chemistry and Environment, ENSA, University Ibn Zohr, PO Box 1136, \\ Agadir, Morocco; \\ ${ }^{2}$ College of Education, Department of Chemistry, Kirkuk University, Kirkuk, Iraq; \\ ${ }^{3}$ Department of Crop Science, College of Sanghur Life Science, Konkuk University, Seoul 05029, \\ South Korea \\ ${ }^{4}$ Department of Chemistry, College of Science, King Khalid University, P. O. Box 9004, Postal Code \\ 61413, Abha, Kingdom of Saudi Arabia; \\ ${ }^{5}$ Chemistry and Environmental Division, Manchester Metropolitan University, Manchester, United \\ Kingdom; \\ ${ }^{6}$ Chemistry Department, Faculty of Science, Minia University, El-Minia, Egypt;

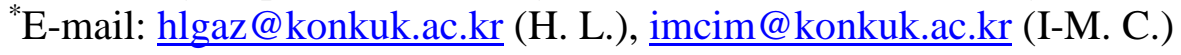

doi: $10.20964 / 2020.09 .95$

Received: 9 May 2020 / Accepted: 16 July 2020 / Published: 10 August 2020

In the last few decades, scientists have been interested in the deterioration and the corrosion of metals and their alloys in the acidic environment, which is widely used in various industrial applications. To develop new strategies that lead to control and inhibit the corrosion of metals, eco-friendly corrosion inhibitors have received a lot of interest in recent years. In this context, the main goal of the current study is to determine the functionality of two new synthesized hydrazone derivatives as potential corrosion inhibitors for mild steel in acidic $\mathrm{HCl}$ solution. To achieve this goal, the corrosion inhibition behavior of (E)-N'-(4-methoxybenzylidene)-2-(6-methoxynaphthalen 2-yl)propanehydrazide (HYD-3) and N'-cyclohexylidene-2-(6-methoxynaphthalen-2-yl)propanehydrazide (HYD-4) on MS was studied by employing electrochemical techniques in combination with surface characterization with the help of SEM-EDS analysis. As a result of these investigations, the two inhibitors exhibited excellent protection efficiency, and the best inhibition effect was shown by HYD-3 (90\% at $\left.5 \times 10^{-3} \mathrm{M}\right)$. Potentiodynamic polarization (PDP) results demonstrated that the two inhibitors are mixed-type inhibitors and that the adsorption isotherm of these molecules responds to the Langmuir model. Further analysis obtained by impedance spectroscopy (EIS) tests showed that the studied inhibitors make a positive impact on the mild steel corrosion process by increasing the polarization resistance with an increase in the concentration of the inhibitor. Another important practical result is that the SEM-EDS 
morphological information suggested that the studied compounds form protective films onto the MS surface. Further, the impact of solution temperature and immersion time on HYD-3 performance has been evaluated. Finally, this work demonstrated significantly improved steel corrosion resistance and could pave a way to develop new-tagged inhibitors in this field.

Keywords: Corrosion inhibition; Mild steel; HCl; Hydrazone derivative; EIS; SEM/EDX.

\section{$\underline{\text { FULL TEXT }}$}

(C) 2020 The Authors. Published by ESG (www.electrochemsci.org). This article is an open access article distributed under the terms and conditions of the Creative Commons Attribution license (http://creativecommons.org/licenses/by/4.0/). 